\title{
Analysis of Wear in Organic and Sintered Friction Materials Used in Small Wind Energy Converters
}

\author{
Jorge Alberto Lewis Esswein Junior ${ }^{\mathrm{a} *}$, Fabiano Edovirges Arrieche ${ }^{\mathrm{a}}$, Lírio Schaeffer ${ }^{\mathrm{b}}$ \\ ${ }^{\mathrm{a}}$ Grupo de Desenvolvimento em Energias Renováveis - GDER, Centro de Tecnologia, \\ Universidade Federal do Rio Grande do Sul - UFRGS, \\ Av. Bento Gonçalves, 9500, 91501-970 Porto Alegre - RS, Brazil \\ ${ }^{\mathrm{b}}$ Laboratório de Transformação Mecânica - LdTM, Centro de Tecnologia, \\ Universidade Federal do Rio Grande do Sul - UFRGS, \\ Av. Bento Gonçalves, 9500, CP 15021, 91501-970 Porto Alegre, RS, Brazil
}

Received: January 9, 2008; Revised: May 18, 2008

\begin{abstract}
Wind energy converters of small size used in isolated units to generate electrical energy must present low maintenance cost to such facilities economically viable. The aspect to be analyzed in cost reduction is the brake system, since in isolated systems the use of brake is more frequent reducing the brake pads life time. This study aims at analyzing the wear behavior of some materials used in brake pads. An organic material was analyzed comparing it with a commercial brake pad, and the sintered material was developed and tested. The materials behaviors were evaluated in both wear and friction coefficient. The sintered samples were made by powder metallurgy. The composition was compacted at $550 \mathrm{MPa}$ and sintered in a furnace with controlled atmosphere to avoid oxidation. Despite the different compositions of the two types of materials, they presented a very similar wear; however, the sintered material presented a higher friction coefficient. An adjustment in the braking system of the wind generator might be proposed to use the sintered brake pad, due to its higher friction coefficient. Consequently, the braking action becomes lower, reducing the wear rate of the material.
\end{abstract}

Keywords: friction materials, wear, wind energy converters, brake pads, powder metallurgy

\section{Introduction}

Due to an increase in the demand of electrical energy and the difficulty some people have to have access to this source; a proposal was developed to create units of independent energy supply for places which are isolated from the available electrical net. These units would be hybrid systems of electrical energy acquisition, and would count on the use of wind energy, solar energy and energy acquired by an oil generator ${ }^{1}$. Another problem currently faced is the high cost of oil and commodities for energy generation, which brings about the necessity of extending the generating sources of energy ${ }^{2}$. The present study focuses on improving the performance and autonomy of wind energy converters of small size that will be used in these systems. To make the installation of these units feasible, the maintenance cost must be the lowest possible; therefore, a system of efficient brake is very important for this project. As the use in hybrid systems has a different proposal, the three types of electrical energy acquisition mentioned are used to load batteries, storing this energy. When the system is loaded, the use of the wind converter brake becomes necessary and, consequently, the brake is requested more often demanding more brake pads adjustments and replacements, which makes this system very expensive, since the maintenance cost is very high. The current brake system used in wind converters of small size is detailed in Figure 1.

The present study aims at comparing the efficiency of the brake pad made of phenolic resin (or organic), widely used in the market, to the friction materials made by powder metallurgy.

\section{Friction Materials}

The basic objective when using friction materials is to convert kinetic energy into thermal energy, promoting a decrease or total stop of movement. This thermal energy is usually dissipated by friction materials, and because of that they present good thermal conductivity. Besides this characteristic, friction materials present good friction coefficient and low wear rate, supplying the brake system with a high performance. Friction materials for brake systems typically contain metallic materials to improve their wear resistance, thermal diffusivity and strength. Several metallic materials such as copper, steel, iron, brass, bronze, and aluminum have been used in the form of fibers or particles in friction material, and it is known that type, morphology, and hardness of the metallic ingredients can affect friction and wear of friction materials ${ }^{3}$.

\subsection{Organic-based friction materials}

The production process usually used for organic-based friction materials is the hot pressing. Organic-based brake pads are usually made of composite materials. Ten to twenty different components are used $^{12}$, but the following structural components are necessary ${ }^{4}$ :

- Structural materials: for the supply of mechanical resistance. Metallic fibers, carbon, glass, etc. are usually the ones used;

- Additives: for lubrication and stabilization of friction materials (graphite or metallic sulfides) or to promote cleaning of the disc surfaces through grindability (alumina and silica);

- Fillers: to improve the production cost (silicon base oxide and barium sulphate); and 
- Bonds: for bonding and the fulfillment of the pad materials, forming a thermally stable compound (phenolic resins) where sometimes anti-noise (elastomer) materials can be added.

\subsection{Friction materials by powder metallurgy}

Friction materials made by powder metallurgy present a metallic matrix, which reflects in higher resistance to heat and good resistance to wear ${ }^{5}$. Bronze is generally used as the base metal because it presents a good thermal conductivity and it also helps maintain the friction coefficient in high temperatures ${ }^{6}$. Iron, silica and graphite are other materials that compose a sintered brake pad. Iron helps increase wear resistance and friction ${ }^{7}$, while silica, being an abrasive, helps the increasing of the friction coefficient. According to current research, it is still hard to explain the relation among the materials that compose a brake pad and the friction behavior and improvements in the composition of these materials are usually tested by trial and error ${ }^{8}$.

Metal-to-metal contacts friction and wear have been studied extensively and plenty of information can be found in tribology literature; see example in ${ }^{9}$. The sliding characteristics of metal pairs are understood in terms of "compatibility" of the two metals based on an adhesion mechanism of pure metals at the friction interface ${ }^{10,11}$. The friction coefficient obtained from pure metal-to-metal contact, however, often differs from the ones made of a composite containing metals sliding against a metallic counter surface; and this discrepancy is due to influences of other ingredients in the composite.

\section{Experimental Studies}

\subsection{Alloys composition}

The resin-based friction material to be compared with the tested material is made in Germany by a brake pads manufacturing company called Lucas. Its chemical composition is not presented in the study because the manufacturer does not provide information on composition or manufacturing process. Lucas Brake Pads are manufactured by TRW Automotive and have always been the benchmark for the European car market, as well as being the leading supplier of disc brake systems to vehicle manufacturers including Mercedes ${ }^{\circledR}$, Audi $^{\circledR}$, Volvo $^{\circledR}$, Suzuki $^{\circledR}$, General Motors ${ }^{\circledR}$, Ford $^{\circledR}$, Nissan $^{\circledR}$, Toyota ${ }^{\circledR}$ and Mitsubishi ${ }^{\circledR 13}$.

The tested composition of the material produced by powder metallurgy is described in Table 1 . The powder alloy was made in a type $\mathrm{Y}$ mixer, mixing it for 30 minutes. Graphite was added in the

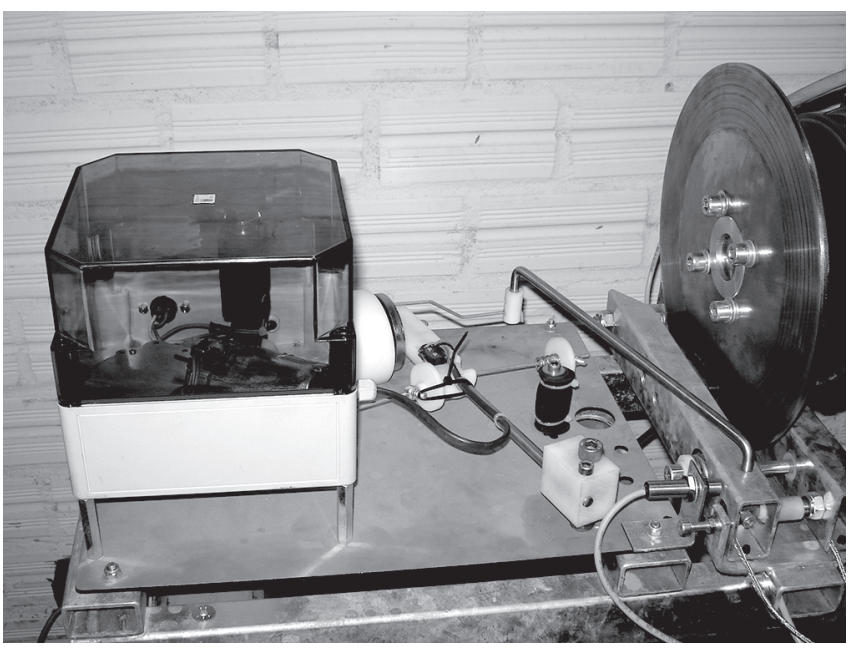

Figure 1. Braking system of Wind Energy Converter (WEC). last 10 minutes because it is a lubricant and powder materials tend to separate again if graphite stays for too long in the alloy.

\subsection{Compaction}

The samples compaction was held in a unidirectional press of the brand EKA, with a capacity for $400 \mathrm{kN}$ and simple action. In order to avoid the density gradient effect, a system of floating compaction was used. The pressure used during the compacting process was of $550 \mathrm{MPa}$. The sample (Figure 2) used in the experiments presents the dimensions of $18 \mathrm{~mm}$ diameter $\times 11.5 \mathrm{~mm}$ height. Zinc stearate was used as lubricant for the matrix walls, and it is responsible for helping in the extraction of the compacting matrix sample.

\subsection{Sintering}

The samples sintering were held in a tubular furnace in a temperature of $810^{\circ} \mathrm{C}$. A protective atmosphere of gas $\left(24 \%\right.$ of $\mathrm{H}_{2}-76 \%$ of $\mathrm{N}_{2}$ ) was used to avoid oxidation during the process, since copper requires a high reducer agent to avoid this effect. The furnace was heated in a temperature of $810^{\circ} \mathrm{C}$ in 30 minutes, and was kept in the same temperature for more 45 minutes. Then, it was allowed to reach room temperature naturally.

Figure 3 shows the heating process. After sintering, the material presented an increase in volume and a slight loss in mass, which indicates that the material presents increasing porosity and decreasing density. Controlled porosity in this type of friction material is acceptable because it increases the roughness of the material, providing a better friction. The existent porosity in the material also gives this material the possibility of returning into friction materials to the copper matrix.

Table 1. Mixture Composition in \% of weight.

\begin{tabular}{lc}
\hline \multicolumn{3}{c}{ Sample MP65 } \\
\hline Material & Mass $(\%)$ \\
\hline Copper & 65 \\
Tin & 7 \\
Iron & 10 \\
Silica & 8 \\
Graphite & 10 \\
\hline
\end{tabular}

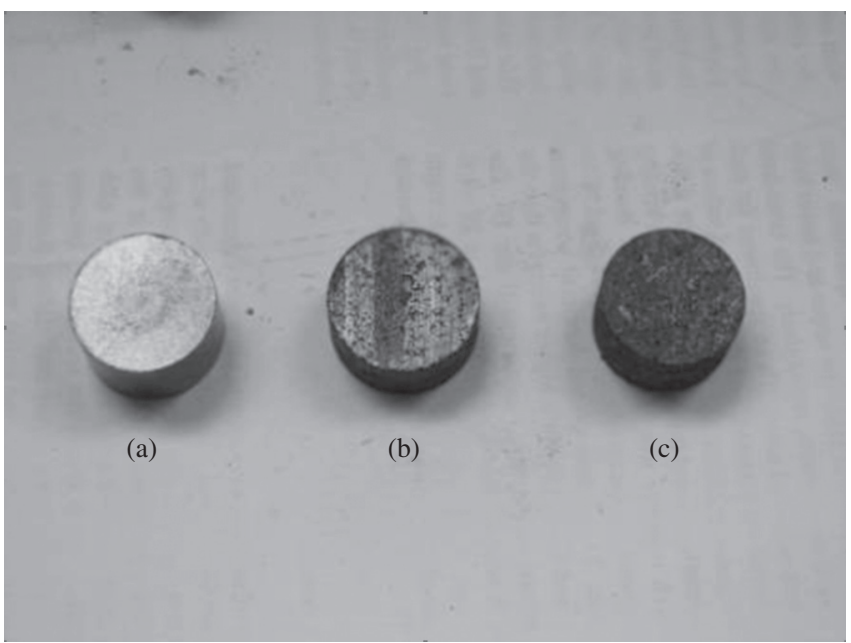

Figure 2. (a) MP65 compacted; (b) MP65 sintering; and (c) Lucas Sample. 


\subsection{Tests performance}

The samples were submitted to a milling process to guarantee that both the resin-based materials and the sintered materials the same dimensions. The samples' wear test is presented in Figure 4. A commercial automobile brake disc, made of gray cast-iron, was used as abrasive agent. An electrical motor was linked to the disc using a belt in order to start it.

The disc rotates at $1600 \mathrm{rpm}$. The sample was put on a base together with a spring. The samples get in contact with the disc when the spring is constrained inside the base, causing a pressure of $283 \mathrm{kPa}$ against the disc.

\subsubsection{Wear}

The wear test was made by keeping the material pressurized against the disc for ten minutes. The samples mass were measured before and after each test, so it was possible to evaluate the wear suffered by the material. The friction coefficient was measured after each test to make sure the material was well-adjusted with the disc. Wear was measured using the following formula:

$$
\mathrm{W}=\frac{\text { mass loss }(\mathrm{g}) / \text { density }\left(\mathrm{g} \cdot \mathrm{mm}^{-3}\right)}{\text { Traveled Distance }}
$$

The present formula is usually used to analyze wear in friction materials for brakes ${ }^{14}$. The volume of the lost material was calculated dividing the mass loss value by the material density. The covered distance used in the present formula was measured with the equation ( $2 \times \Pi \times \mathrm{R} \times$ Rotation $\times$ Test Timing), where $\mathrm{R}$ is the distance from the sample position to the center of the disc.

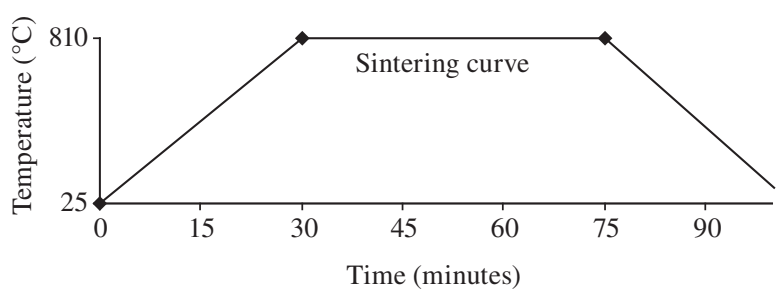

Figure 3. Sintering curve.

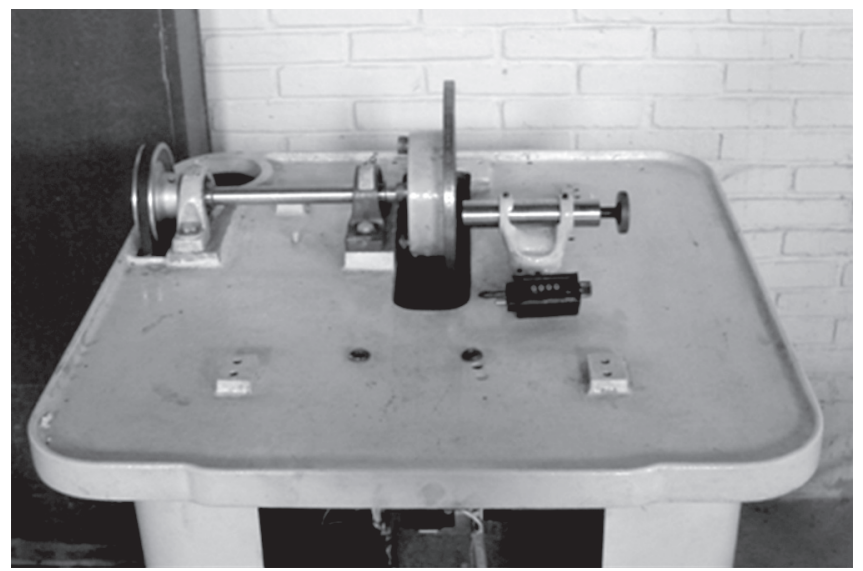

Figure 4. Developed machine to the wear test.

\subsubsection{Friction}

The friction coefficient of the material was calculated using the following formula:

$$
\mu=\frac{I_{z} \omega_{0}}{F_{N} \cdot r}\left(\frac{1}{t_{a}}-\frac{1}{t_{i}}\right)
$$

where:

$\mathrm{Iz}=$ Moment of inertia of the brake disc $\left(\mathrm{kg} \cdot \mathrm{m}^{2}\right)$.

$\omega_{0}=$ Initial angular speed of the disc $(\mathrm{rad} / \mathrm{s})$.

$\mathrm{F}_{\mathrm{N}}=$ Normal force applied to the sample. $(\mathrm{N})$.

$\mathrm{r}=$ Mean radius of normal form application (m).

$\mathrm{t}_{\mathrm{a}}=$ Time the disc takes to stop with normal force applied to the system (s).

$\mathrm{t}_{\mathrm{i}}=$ Time the disc takes to stop only by the system inertia (s).

The times $\left(\mathrm{t}_{\mathrm{a}}\right)$ were measured before and after each wear test to analyze the brake pads behavior at different temperatures.

\section{Results and Discussion}

After sintering, it was possible to verify that the material made by Powder Metallurgy presented a $29 \%$ increase of its volume and a $0.22 \%$ mass loss. Such a high increase in the volume and a low mass loss originated a high increasing of the material porosity (Figure 5). The porosity of the material may cause higher temperature increase when the system operates because the pores work as insulators in the material, and they make the heat transference difficult ${ }^{15}$. In one instance, this increasing in porosity presented some benefits related to the application of the friction material, since it increases the material roughness, promoting an increase in the friction with the brake disc. Another benefit brought about by porosity was to keep the abrasive particles in the material, avoiding their loss during braking action. The mass loss must have occurred because tin presents a lower melting point when comparing with the one used in sintering and, therefore, even before the alloy with copper occurred, part of the tin must have been released from the matrix.

The sintered material density also presented a high decreasing. The density values before and after sintering are described in Table 2 . This chart also describes the resin-based material density, which presented a much lower density when compared to the one presented by the sintered material. As the quantity of metallic material in the sintered is higher than the one in the resin-based material, it is natural that they present such variation in their densities.

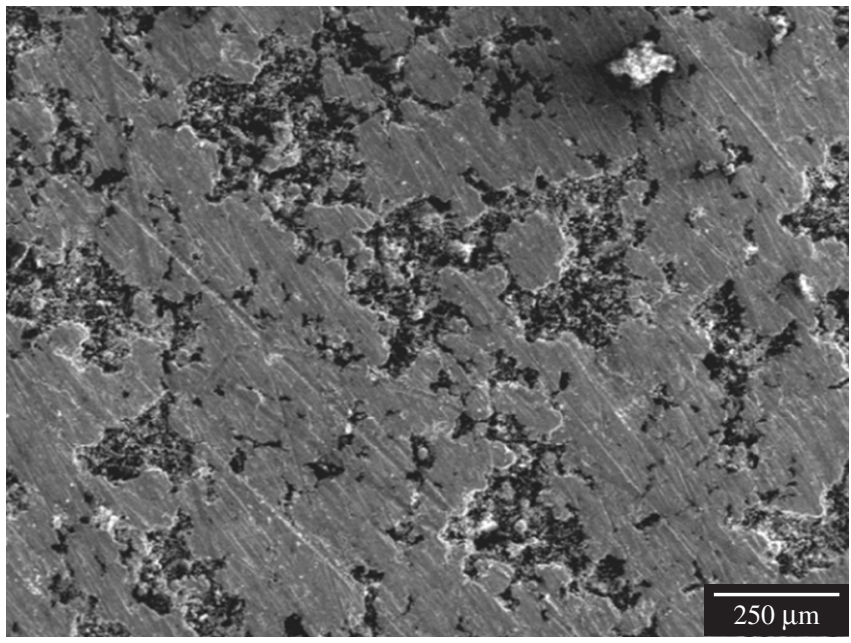

Figure 5. Sample micrography (MP65) after the sintering process. 
The material density was measured using the dimensions of the samples and their mass.

The wear suffered by the tested material is presented in Figure 6. It can be noticed that Sample MP65 suffered less wear than the resinbased pad. In order to be resistant to wear, a material must have a ductile matrix with the addition of hard materials, such as carbides ${ }^{8}$.

Regarding the results obtained with the sintered material, it was possible to obtain a bronze alloy with good ductility. The ductility of the matrix is important in the moment of reabsorbing the particles from the hard materials which get loose during the braking action, keeping them linked in the matrix and therefore, avoiding an excessive material wear.

The materials hardness was also analyzed. The hardness values obtained with the organic-based material and with the metallic-based material were of $180 \mathrm{HB}$ and $10 \mathrm{HB}$, respectively. The sintered materials hardness was too small, most likely due to its high porosity as well as the small hardness of the base metal. This result might have affected the sintered pad in a way that it suffered similar wear to the resin-based pad, no matter what was the metallic base of the material. Despite the very different hardness presented by each material, the sintered material proved to have a superior resistance to compression when compared to the resin-based material, as it can be noticed in the graph in Figure 7.

The friction coefficient proved to be more efficient in the sintered sample. The friction coefficient values are presented in Figure 8.

According to further analysis in the graph presented in Figure 7, it was possible to verify that the sintered material is much more ductile than the resin-based one. As mentioned previously, it is important that the material presents a good ductility because it increases the material's wear resistance.

The friction coefficient value was higher in sample MP, because it presents a higher amount of $\mathrm{SiO}_{2}$, which is approximately the same as graphite. Graphite and $\mathrm{SiO}_{2}$ have contrasting functions. The $\mathrm{SiO}_{2}$ presents the function of lubricating the contact surface. Higher values of silica may increase the friction coefficient even more, but it will harm the brake disc. However, a balanced quantity of this material in the compound should be analyzed. Besides, the addition of silica allows a more adherent contact surface because it removes oxides and other films from the disc surface ${ }^{7}$.

Table 2. Material density.

\begin{tabular}{cc}
\hline Sample & Density $\left(\mathrm{g} \cdot \mathrm{cm}^{-3}\right)$ \\
\hline MP65 - before sintering & 5.413 \\
MP65 - after sintering & 4.174 \\
Organic material & 2.579 \\
\hline
\end{tabular}

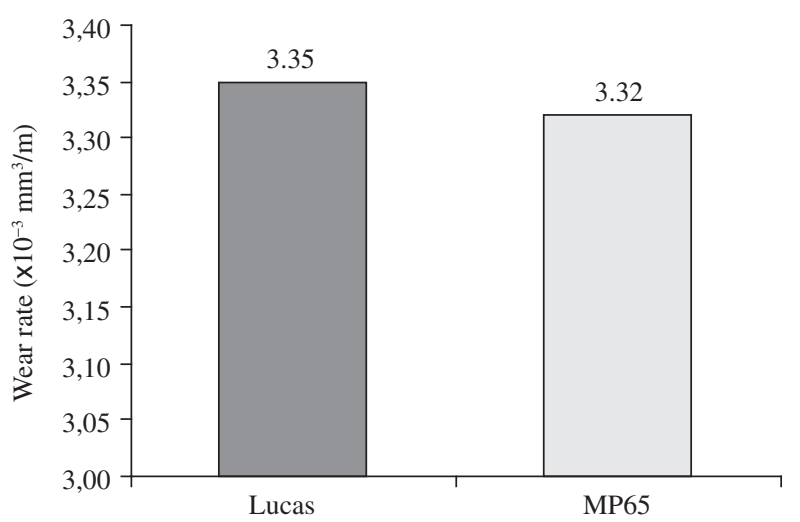

Figure 6. Wear rate of the analyzed materials.

\section{Conclusions}

Based on the results obtained, the sintered brake pad proved to be more efficient than the organic-based pad because it presents a relatively lower wear rate as well as a higher friction coefficient. The wear rate in the sintered material was lower due to the good ductility of its metallic matrix.

Due to the presence of $\mathrm{SiO}_{2}$, it was possible to obtain an increase of the friction coefficient in the sintered material.

In order to obtain an even greater wear resistance of the sintered material, it is necessary to increase its hardness. This can be done using a sintering process under pressure.

To improve the thermal conductivity of the material, it is important to decrease the matrix porosity, so that it is possible to improve the brake pad efficiency.

As previously mentioned, studies about friction materials are based on trial and error testing procedures. It is through changes in the base materials, in the manufacturing processes and even in the work conditions that really different results can be noticed. The present study suggests that each friction material needs a specific focus of study. In regard to the results, it can also be suggested the necessity of increasing of the "brake pad and disc set" lifetime. Because of this, the consequences of the tests on the disc should also be considered.

This study suggests that the materials which are used, the base matrix and manufacturing processes will be chosen independently of their use, that is why the researcher must present good knowledge

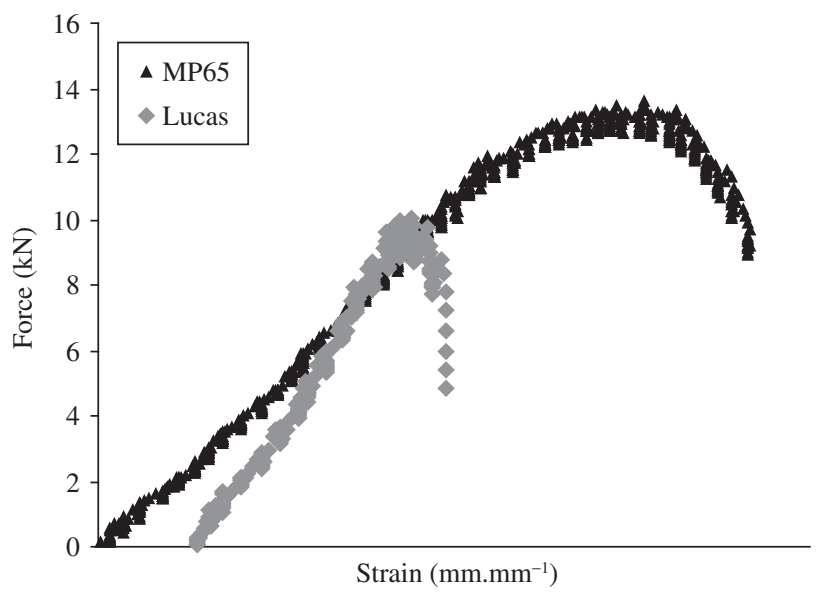

Figure 7. Compression test. Force $x$ Strain.

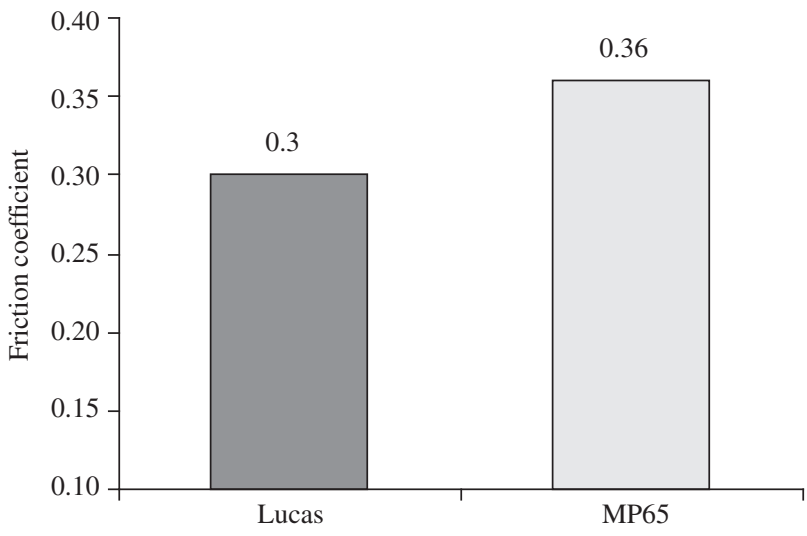

Figure 8. Friction coefficient. 
and he must also be given the adequate conditions to the making of the tests.

\section{Acknowledgements}

The authors wish to acknowledge FAPERGS for financing this project, EPI Energia, Projetos e Investimentos Ltda for its financial, technological and logistical support to this study and also the companies Metalpó, Nacional de Grafite e Mineração Jundu for the supplying of the raw materials.

\section{References}

1. Elhadidy MA, Shaahid SM. Promoting applications of hybrid (wind + photovoltaic + diesel + battery) power systems in hot regions. Renewable Energy. 2004; 29(4):517-528.

2. Deshmukh MK, Deshmukh SS. Modeling of hybrid renewable energy systems. Renewable and Sustainable Energy Reviews. 2008; 12(1):235-249.

3. Anderson AE. Metals Handbook. 19 ed. [S.I.]: ASM; 1992. p. 569-577. Available from: http://products.asminternational.org/hbk/index.jsp

4. Eriksson M, Bergman F, Jacobson S. On the nature of tribological contact in automotive brakes. Wear. 2002; 252(1):26-36.

5. Vicente C. Metalurgia do pó. 4 ed. São Paulo: Associação Brasileira de Metalurgia e Materiais; 2001.
6. Kurt A, Boz M. Wear behavior of organic asbestos based and bronze based powder metal brake linings. Materials and Design. 2005; 26(8):717-721

7. Ho SW, Ho D, Wu KF, Lin CS. Friction Properties of Copper-Based and Iron-Based Friction Material. Advances in Powder Metallurgy. 1991; 1:229-236.

8. Ostermeyer GP. On the dynamics of the friction coefficient. Wear. 2003; 254(9):852-858.

9. Buckley DH. Surface Effects in Adhesion, Friction, Wear and Lubrication, Tribology Series 5. Amsterdam: Elsevier; 1981.

10. Bowden FP, Rowe GW. The adhesion of clean metals. Proc. R. Soc. (London). 1956; A233:429-442.

11. Ferrante J, Smith JR. A theory of adhesion at a bimetallic interface: overlap effects. Surf. Sci. 1973; 38(1):77-92.

12. Yafei L. A combinatorial approach for automotive friction materials: Effects of ingredients on friction performance. Composites Science and Technology. 2006; 66(3-4):591-598.

13. Auto Brakes \& Service. Parts - Disc and Brake Pads. [online]. 2008. Avaliable from: http://www.autobrakeservice.com.au

14. Kueva G, Tschiptschin AP, Sinatora A, Guesser WL. Desgaste de ferros fundidos usados em discos de freios de veículos automotores. In: $8^{\circ}$ International Brake Colloquiun; 2007; Rio Grande do Sul. Brasil: Sae Technical Papers Series; 2001. n. 01, p. 6.

15. Kurt A, Ates $\mathrm{H}$. Effect of porosity on thermal conductivity of powder metal materials. Materials and Design. 2007; 28(1):230-233. 
